\title{
COMPARATIVE ACTIONS OF SALICYLATE ON THE AMPHIBIAN LATERAL LINE AND GUINEA PIG COCHLEA
}

\author{
Jean luc Puel, ${ }^{*}$ Sanford C. Bledsoe, Jr, $†$ Richard P. Bobiin, ${ }^{*} \ddagger$ Gail Ceasar $*$ \\ and MaUREen Fallon* \\ *Louisiana State University Medical School, Kresge Hearing Research Laboratory of the South, \\ Department of Otorhinolaryngology, and Biocommunication, 2020 Gravier Street, Suite A, New Orleans, \\ LA 70012, USA; and †Kresge Hearing Research Institute, University of Michigan Medical School, \\ Ann Arbor, MI 48109, USA. Telephone (504) 568-4785
}

(Received 27 June 1988)

\begin{abstract}
Salicylate actions on afferent nerve activity in the Xenopus lateral line and on cochlear potentials in guinea pig were investigated.

2. In the lateral line, salicylate $(0.3-2.5 \mathrm{mM})$ suppressed spontaneous activity, water motion evoked excitation and responses to L-glutamate $(1-2 \mathrm{mM})$ and kainate $(10-20 \mu \mathrm{M})$.

3 . In the guinea pig, salicylate $(0.6-10 \mathrm{mM})$ suppressed the compound action potential (CAP) and increased NI latency at low but not high sound intensities.

4. In the lateral line salicylate action may involve an antagonism of the hair-cell transmitter on the afferent nerve.

5. In the cochlea salicylate may suppress the active process or cochlear amplifier.
\end{abstract}

\section{INTRODUCTION}

For at least a century, it has been recognized that aspirin (acetylsalicylic acid) can cause tinnitus and hearing loss. The effects are completely reversible, usually 24-72 hr after stopping aspirin ingestion (Macht et al., 1920; McCabe and Dey, 1965; Mongan et al., 1973). The toxicity has been attributed to the salicylate ion since sodium salicylate produces a reversible increase in auditory threshold at concentrations comparable to those present in blood following the administration of aspirin (Myers and Bernstein, 1965; Gold and Wilpizeski, 1966; Silverstein et al., 1967).

To date, the literature cannot explain the precise nature of the hearing loss due to salicylate although the cochlea appears to be the primary site of action (Jastreboff and Sasaki, 1986). For example, Silverstein et al. (1967) reported that both the cochlear microphonic (CM) and the compound action potential of the auditory nerve (CAP) were depressed in cats following intraperitoneal injection of sodium salicylate. McPherson and Miller (1974) reported the same effect in guinea pigs following intragastric injection of choline salicylate. These results suggest that the hair cells of the cochlea are affected by salicylate. On the other hand, Mitchell et al. (1973) observed only the decrease in CAP following subcutaneous administration of sodium salicylate to guinea pigs and concluded that salicylate affected the auditory nerve and not the hair cells. The results of Thalmann et al. (1973), Thalmann (1975) and Bobbin and Thompson (1978) which showed that

¥Author to whom correspondence should be addressed. salicylate reduced the CAP without affecting $\mathrm{CM}$, support this conclusion.

The present study was designed to provide additional information about the effects of salicylate. We examined a hypothesis first suggested by Mitchell et al. (1973) that salicylate may have an action at the hair cell-afferent nerve synapse. Since L-glutamate appears to be the hair cell transmitter (Bledsoe et al., 1988), we tested the effects of salicylate on responses to L-glutamate, spontaneous activity and water motion induced excitation of afferent nerve fibers innervating hair cells in the lateral line of Xenopus laevis. For a comparison and to determine if the results obtained in the lateral line could possibly account for the actions of salicylate in the cochlea we also examined the effects of salicylate on guinea pig cochlear potentials looking for actions which could be explained by an antagonism of the action of the hair cell transmitter. A preliminary report has been presented (Bobbin et al., 1985c).

\section{MATERIALS AND METHODS}

Lateral-line experiments were performed on adult male or female African clawed frogs, Xenopus laevis. The techniques for anesthetizing the animals, removing a portion of skin containing the lateral-line organ, the in vitro methods for isolating and recording afferent nerve activity from a single cluster of hair cells (stitch), and applying drugs to the inner surface of the skin were as previously described (Bledsoe and Bobbin, 1982; Bledsoe et al., 1983; Bobbin et al., 1985a, b). The posterior lateralis nerve trunk was dissected free from connective tissue and action potentials from the two afferent nerve fibers innervating a selected stitch were recorded extracellularly with a suction electrode, digitized and counted with a ratemeter in $30 \mathrm{sec}$ time bins. The inner 
surface of the skin was continuously washed with frog Ringer solution at room temperature $\left(20-23^{\circ} \mathrm{C}\right)$ except during periods of drug testing. The Ringer solution, which flowed at a rate of $2 \mathrm{ml} / \mathrm{min}$, had the following composition (mM): $\mathrm{NaCl}, 110 ; \mathrm{KCl}, 2.0 ; \mathrm{CaCl}_{2}, 1.8 ; \mathrm{Na}_{2} \mathrm{HPO}_{4}, 2.25$; $\mathrm{NaH}_{2} \mathrm{PO}_{4}, 0.75 ; \mathrm{pH}, 7.0$. The preparation described by Bobbin et al. (1981) was used to study the effects of salicylate on afferent nerve responses to glutamate and other excitatory amino acids. Responses to agonists were obtained during an initial drug-free Ringer wash, 40 min after starting a wash containing salicylate and again $20-30 \mathrm{~min}$ after washing the preparation with the drug-free Ringer solution. For each response, $2 \mathrm{~min}$ of spontaneous activity were recorded, then a $1 \mathrm{ml}$ volume of agonist solution with or without salicylate was injected into the tube delivering the Ringer wash. The activity before drug application was used to calculate a mean spontaneous firing rate. The difference in the peak excitation elicited by an agonist and the pre-drug spontaneous level in the presence of salicylate was expressed as a percentage of that obtained in its absence.

The effects of salicylate on water motion-induced responses of the afferent nerve fibers were evaluated as previously described (Bledsoe and Bobbin, 1982; Bobbin et al., 1985a, b). Isolated skins were held on the end of a plastic cylinder with a Neoprene O-ring and the external (cupular) surface of the skin facing down into a water-filled chamber. A glass rod attached to the cone of a loudspeaker was positioned $0.5-1.0 \mathrm{~mm}$ beneath a selected stitch and vibrated at a frequency of $35 \mathrm{~Hz}$ with a sinusoidal voltage. $\Lambda$ microcomputer controlled stimulus on, off, and magnitude. Stimulus magnitude was set at $9 \mathrm{~dB}$ above the threshold of excitation. Threshold was established with audiovisual cues and defined as the intensity needed to produce a just detectable increase in spontaneous discharge rate. For testing, the Ringer wash (with or without salıcylate) was turned off and 3 alternating $30 \mathrm{sec}$ periods of spontaneous and stimulated activity were recorded in $10 \mathrm{sec}$ time bins in the absence or presence of salicylate in $200 \mu \mathrm{l}$ of Ringer solution placed in the experimental chamber to cover the inner surface of the skin. Mean spontaneous and stimulated firing rates were calculated from the second and third time bins in each of the 3 samples of spontaneous and stimulated activity. These values, as well as the difference between them, in the presence of salicylate were expressed as a percentage of those obtained in its absence.

Cochlear experiments were performed on 12 pigmented guinea pigs, Catia cobaya, of either sex using methods similar to those previously described (Bobbin and Ceasar, 1987). The animals were anesthetized with chlorprothixene (Taractan, $25 \mathrm{mg} / \mathrm{kg}$, i.p.) and pentobarbital (Nembutal, $30 \mathrm{mg} / \mathrm{kg}$, 1.p.), and artificially respired. During experiments, additional pentobarbital was adminstered $(25 \mathrm{mg} / \mathrm{kg}$, i.p.) to assure a deep level of anesthesia and rectal temperature was maintained at $37-39^{\circ} \mathrm{C}$. The right cochlea of each animal was exposed ventrolaterally and both middle ear muscles sectioned.

The CAP (N1 - P1), N1 latency, CM and summating potential (SP) were recorded from a $200 \mu \mathrm{m}$ enamelinsulated silver wire placed in a hole in the scala vestibuli of the basal turn, amplified, averaged ( 20 samples) and stored on a computer. The potentials were evoked by $10 \mathrm{kHz}$ tone bursts having $0.25 \mathrm{msec}$ exponential rise-fall times, $10 \mathrm{msec}$ duration and $200 \mathrm{msec}$ interstimulus interval. Intensity functions were obtained by varying tone burst intensities (2-104 dB SPL, in $6 \mathrm{~dB}$ steps). For measurement purposes, the stored voltages were directed into a filter with a low pass setting of $2 \mathrm{kHz}$ for CAP, N1 latency and SP or a band pass of 7.5 to $15 \mathrm{kHz}$ for $\mathrm{CM}$, and the output of the filter was displayed on an oscilloscope. The threshold of CAP was defined as the dB SPL needed to elicit a measurable response $(\geq 5 \mu \mathrm{V})$ which increased in magnitude with the next step increase in sound intensity.
Artificial perilymph solutions were infused into the basal turn scala tympani and allowed to flow out of the basal turn scala vestibuli at approximately $0.6 \mu 1 / \mathrm{min}$ for $10 \mathrm{~min}$ through holes made in the cochlea. The composition of the artificial perilymph was similar to that used previously (Bobbin and Ceasar, 1987) and had a composition of (mM): $\mathrm{NaCl}, 137 ; \mathrm{KCl}, 5 ; \mathrm{CaCl}_{2}, 2 ; \mathrm{MgCl}_{2}, 1$; Hepes, 1 ; glucose, 11; pH 7.4. The two drug solutions tested were sodium salicylate (salicylate) and for an osmotic control, alphaketoglutarate. The salicylate and alpha-ketoglutarate were initially dissolved in artificial perilymph to make a $20 \mathrm{mM}$ concentration and the $\mathrm{pH}$ adjusted to 7.4. Dilutions were then made to yield concentrations tested (mM): $20,10,5$, $2.5,1.25,0.625,0.312$ and 0.156 . In all animals, artificial perilymph without drug was the first perfusion. This was then followed by successive perfusions with increasing concentrations of the drug from 0.156 to $20 \mathrm{mM}$. All drug perfusions were followed by another $10 \mathrm{~min}$ perfusion with artificial perilymph without drug. Intensity functions were obtained before and immediately (within $2 \mathrm{~min}$ ) after each perfusion.

To quantify the effect of the salicylate, we carried out statistical tests on data obtained at: (1) a high sound intensity ( $98 \mathrm{~dB}$ SPL) before turnover of the CM potential, and (2) from a low intensity (62 dB SPL) which yielded potentials (CAP, N1 latency, CM and SP) after the drug treatment which were above the noise of the recording system. Analysis of variance and Newmann-Keuls multiple range tests were used to determine significance $(P<0.01)$. The data are expressed as mean $\pm \mathrm{SE}$.

\section{RESULTS}

In the lateral line salicylate blocked spontaneous activity and the increase in afferent nerve activity evoked by L-glutamate and kainic acid in a dose responsive manner (Fig. 1; Table 1). The lowest concentration to have an antagonist effect was $0.30 \mathrm{mM}$ whereas at $2.5 \mathrm{mM}$ salicylate totally abolished spontaneous activity and the responses to glutamate and kainate. Water motion induced increases in afferent activity were more resistant to the blocking actions of salicylate. Salicylate at concentrations up to $1.25 \mathrm{mM}$ reduced spontaneous activity without a marked suppressive effect on evoked activity (Fig. 2; Table 2) whereas $2.5 \mathrm{mM}$ abolished both spontaneous and evoked activity (Fig. 2; Table 2). At $2.5 \mathrm{mM}$ the effects of salicylate were partially reversible.

In the guinea pig cochlea the initial perfusion solution in each animal was artificial perilymph without drug. This perfusion produced a very small change in the cochlear potentials whereas subsequent perfusions with the same solution resulted in little additional change. Thus all drug effects are compared to potentials recorded after the first perfusion.

Artificial perilymph solutions containing salicylatc induced a dose response suppression of the sound evoked CAP, increased N1 latency at a given low intensity and did not affect CM or SP (Figs 3 and 4). The only significant change on CAP threshold with alpha-ketoglutarate occurred at $20 \mathrm{mM}$ whereas with salicylate the CAP threshold was raised significantly beginning at concentrations of $0.6 \mathrm{mM}$ (Table 3). In addition, the N1 latency at the CAP threshold was significantly decreased by salicylate but not by alpha-ketoglutarate (Table 3). The effect of salicylate on CAP threshold responses was obtained by subtracting the threshold change produced by 

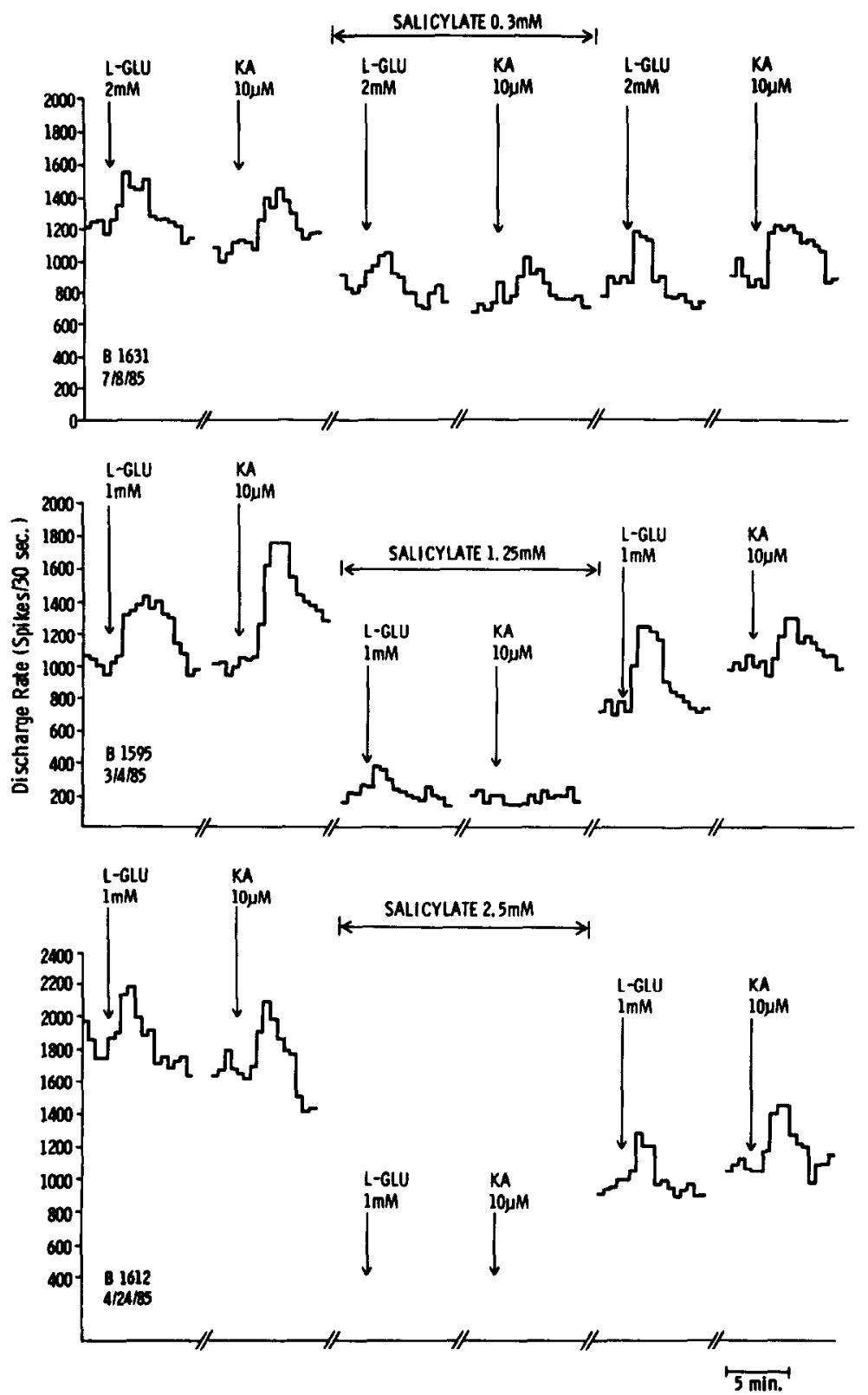

Fig. 1. Responses of lateral line afferent fibers to exogenously applied L-glutamate (L-GLU) and kainate (KA) in the presence of $0.3 \mathrm{mM}, 1.25 \mathrm{mM}$ and $2.5 \mathrm{mM}$ salicylate. Results are from 3 different experiments.

Table 1. Depression* of amino acid induced excitation and spontaneous activity by salicylate

\begin{tabular}{cccc}
\hline $\begin{array}{c}\text { Salicylate } \\
\text { concentration } \\
(\mathrm{mM})\end{array}$ & $\begin{array}{c}\text { Spontaneous } \\
\text { activity } \\
(\%)\end{array}$ & $\begin{array}{c}\text { Amino acid-induced } \\
\text { activity }(\%)\end{array}$ \\
\hline 0.3 & $37 \pm 4$ & $35 \pm 36$ & $46 \pm 17$ \\
& $n=6$ & $n=5$ & $n=3$ \\
0.6 & $65 \pm 11$ & $57 \pm 10$ & $59 \pm 11$ \\
& $n=4$ & $n=4$ & $n=4$ \\
1.25 & $87 \pm 5$ & $78 \pm 15$ & $94 \pm 1$ \\
& $n=2$ & $n=2$ & $n=2$ \\
2.5 & $100 \pm 1$ & $87 \pm 11$ & $92 \pm 3$ \\
& $n=3$ & $n=3$ & $n=3$ \\
\hline
\end{tabular}

* Represented is the percentage (mean $\pm S E$ ) reduction from preblocker responses. 


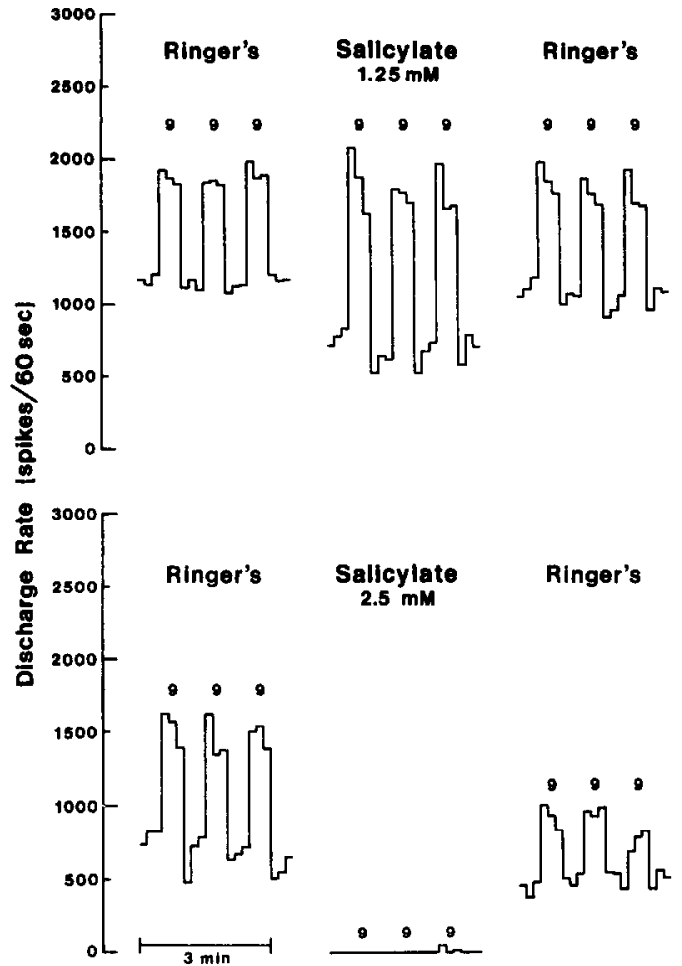

Fig. 2. Effect of $1.25 \mathrm{mM}$ and $2.5 \mathrm{mM}$ salicylate (salicylate) on spontaneous activity and water motion-induced excitation of lateral line afferent nerve fibers. Shown are results from two preparations (top and bottom panels) obtained in the presence of $200 \mu 1$ of drug-free Ringer solution, $40 \mathrm{~min}$ after washing the preparation with salicylate, and again $30 \mathrm{~min}$ after a drug-free Ringer wash. An initial $30 \mathrm{sec}$ of spontaneous activity followed by three alternating $30 \mathrm{sec}$ periods of stimulated and spontaneous activity were recorded in $10 \mathrm{sec}$ time bins. Stimulus intensity was $9 \mathrm{~dB}$ re threshold.

alpha-ketoglutarate from the change produced by salicylate (Table 3). The data in Table 3 reveal the maximum effect of salicylate occurred at about $5 \mathrm{mM}$.

Statistical examination revealed that salicylate significantly reduced the magnitude of the CAP evoked by low intensity tone bursts (62 dB SPL) in concentrations beginning at $1.25 \mathrm{mM}$ (Fig. 4).

Table 2. Effects of salicylate on spontaneous activity and water motion-1nduced excitation

\begin{tabular}{lccc}
\hline $\begin{array}{l}\text { Application } \\
\text { technique }\end{array}$ & $\begin{array}{c}\text { Salicylate } \\
\text { concentration } \\
(\mathrm{mM})\end{array}$ & $\begin{array}{c}\text { Spontaneous } \\
(\%)\end{array}$ & $\begin{array}{c}\text { Water } \\
\text { Motion-induced } \\
(\%)\end{array}$ \\
\hline Wash & 1.25 & $-73 \pm 4$ & $+1.8 \pm 7$ \\
& & $n=5$ & $n=5$ \\
Wash & 2.5 & $-100 \pm 0$ & $-95 \pm 2$ \\
& & $n=4$ & $n=4$ \\
$200 \mu 1$ & 125 & $-42 \pm 5$ & $+31 \pm 4$ \\
& & $n=7$ & $n=7$ \\
$200 \mu 1$ & 2.5 & $-73 \pm 4$ & $-21 \pm 5$ \\
& & $n=4$ & $n=4$ \\
\hline
\end{tabular}

Results are expressed as the percentage (mean $\pm S E$ ) change from preblocker responses, $(+)$ denotes enhancement and $(-)$ suppression.

Water motion-induced activity obtanned at $9 \mathrm{~dB}$ above threshold as described in methods. Salicylate was applied in the Ringer wash for $40 \mathrm{~min}$ or as a $200 \mu \mathrm{l}$ volume which remained in the experimental chamber for $\mathbf{4 0}$ min prior to testing.
However, salicylate had no effect on CAP magnitude evoked by high-intensity tone bursts ( $98 \mathrm{~dB}$ SPL, not shown but see Fig. 3). In comparison alpha-ketoglutarate which only affected CAP at $20 \mathrm{mM}$, reduced responses to both low (Table 3) and high intensity tone bursts. N1 latency at a given low sound intensity ( $62 \mathrm{db}$ SPL) was significantly increased by salicylate beginning at $2.5 \mathrm{mM}$ (Fig. 4). Consistent with the CAP amplitude data, N1 latency at a given high intensity ( $98 \mathrm{~dB}$ SPL) was not affected by salicylate (not shown but see Fig. 3). The control, alphaketoglutarate, did not affect N1 latency (Fig. 4). The SP to low intensity tone bursts (62 dB SPL) was significantly reduced by high concentrations of both salicylate (10 and $20 \mathrm{mM}$ ) and alpha-ketoglutarate (20 mM) (Fig. 4). In contrast, neither salicylate nor alpha-ketoglutarate significantly changed SP evoked by high-intensity ( $98 \mathrm{~dB}$ SPL) sound. The CM to both low- (62 dB SPL; Fig. 4) and high- ( $98 \mathrm{~dB}$ SPL) intensity tone bursts was not significantly altered by either salicylate or alpha-ketoglutarate. All these changes exhibited a partial recovery after a final perfusion with artificial perilymph without drug (Fig. 4).

In two animals recovery was examined after a single perfusion of $5 \mathrm{mM}$ salicylate. In both animals the salicylate induced a suppression of the CAP similar to that obtained with $5 \mathrm{mM}$ salicylate in the cumulative salicylate paradigm. Subsequent perfusion of artificial perilymph induced a complete recovery of the CAP.

\section{DISCUSSION}

In the lateral line salicylate suppressed spontaneous activity and responses to L-glutamate and kainate in a dose responsive manner. In higher concentrations, yet at the same concentration that was required to completely block L-glutamate and kainate, salicylate antagonized the effect of natural stimulation (i.e. water motion). These results support the hypothesis that salicylate antagonizes the hair cell transmitter. The observation that higher concentrations of salicylate were necessary to block natural stimulation than was necessary to antagonize the effects of exogenously applied L-glutamate is common in the study of neurotransmitter antagonists (Davies et al., 1984, 1986). On the other hand, this could indicate that the effect of salicylate was due to a nonselective mechanism such as blockade of an ion channel. Unfortunately, we could not test the selectivity of the glutamate block since other excitatory substances in the lateral line either act on L-glutamate receptors or on acetylcholine receptors, the latter which appear to act through the release of L-glutamate, the putative hair cell transmitter (Bobbin et al., 1985b).

Cochlear perfusion of salicylate resulted in a dose responsive suppression of CAP and an increase in N1 latency which were not observed with the same concentrations of alpha-ketoglutarate. This indicates that the actions of salicylate were not due to nonspecific physical alterations in the cochlea such as might be brought about by osmotic effects. In addition, the concentrations of salicylate found effective on both the lateral line and cochlea are the 

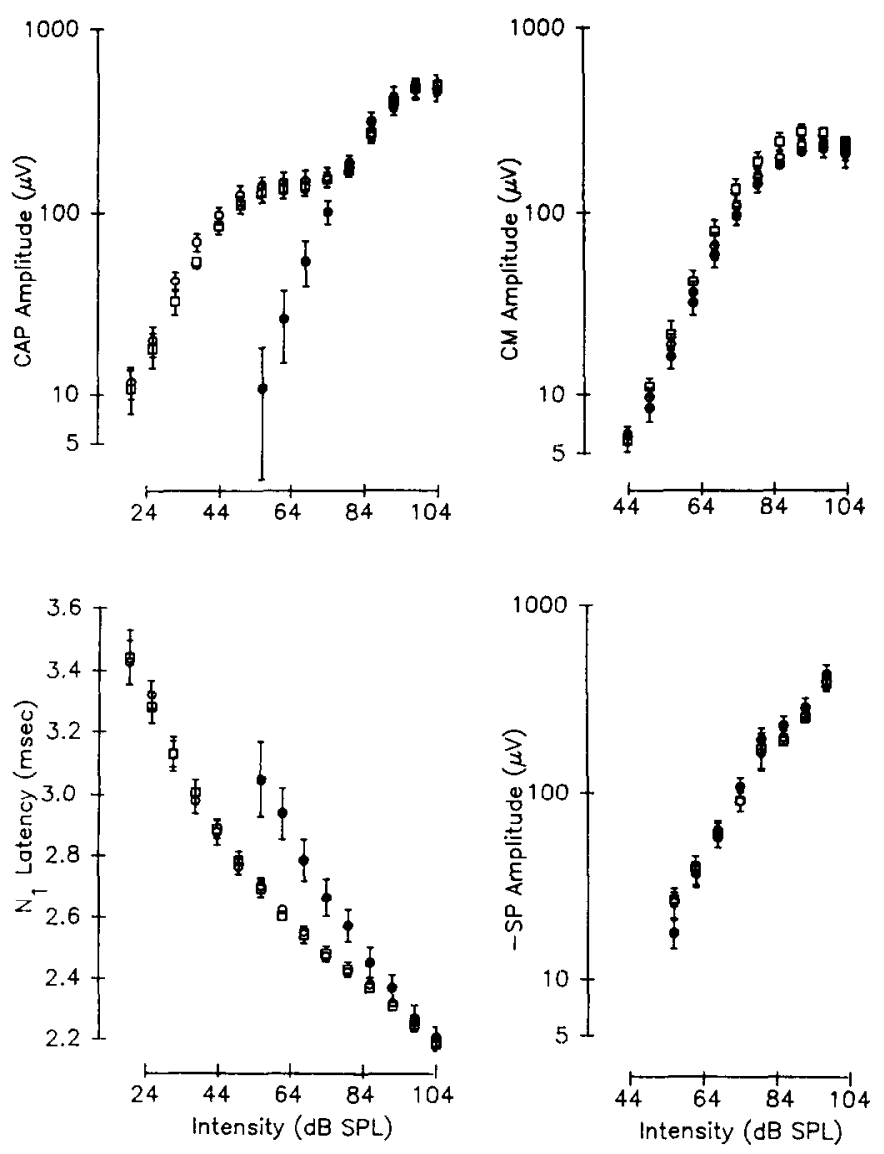

Fig. 3 Effect of salicylate on CAP, N1 latency, CM and SP input-output functions evoked by $10 \mathrm{kHz}$ tone-bursts. Shown are input-output functions obtained before any perfusion (O), after perfusion with artificial perilymph alone before drug ([]), and after perfusing $10 \mathrm{mM}$ salicylate $(\boldsymbol{O})$.
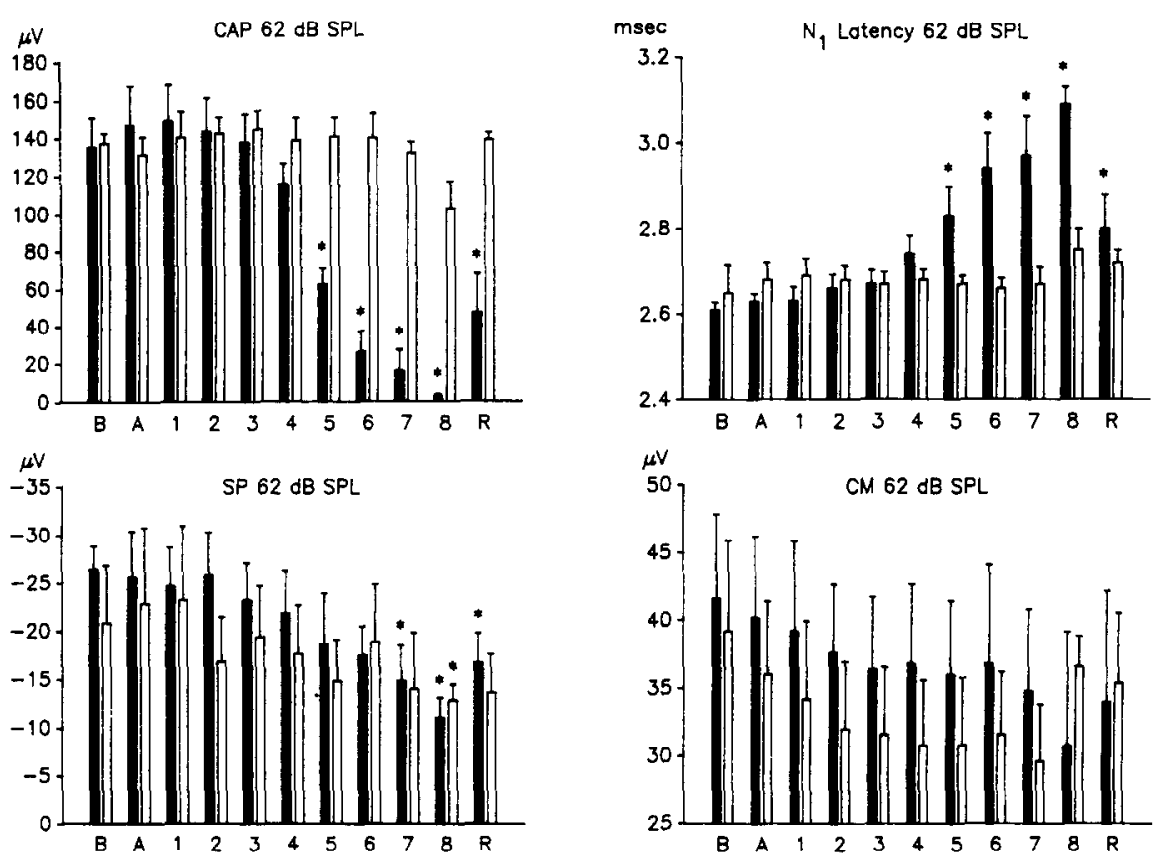

Fig. 4. Effect of increasing concentrations of salicylate (black bars; $n=5$ ) and alpha-ketoglutarate (white bars; $n=5$ ) on the CAP. N1 latency, SP and CM. Shown are the data evoked by tone bursts of $62 \mathrm{~dB}$ SPL before any perfusions (B) and after perfusion with artificial perilymph along before drug (A), successive perfusions of increasing concentrations of salicylate: $0.15 \mathrm{mM}$ (1); $0.31 \mathrm{mM}$ (2); $0.62 \mathrm{mM}$ (3); $1.25 \mathrm{mM}(4) ; 2.5 \mathrm{mM}(5) ; 5 \mathrm{mM}(6) ; 10 \mathrm{mM}(7) ; 20 \mathrm{mM}(8)$, and a post drug artificial perilymph (R). Asterisks indicate a statistically $(P<0.01)$ significant difference from the value obtained after perfusion with artificial perilymph alone before drug (A) 
Table 3. Effects of salicylate and alpha-ketoglutarate (control) on the CAP threshold (dB) and N1 latency (msec) measured at CAP threshold in the guinea pig

\begin{tabular}{lccccc}
\hline $\mathrm{mM}$ & $\begin{array}{c}\text { Control } \\
\mathrm{dB}^{*}\end{array}$ & $\begin{array}{c}\text { Control } \\
\text { msec } \dagger\end{array}$ & $\begin{array}{c}\text { Salicylate } \\
\mathrm{dB}^{*}\end{array}$ & $\begin{array}{c}\text { Salicylate } \\
\text { msec } \dagger\end{array}$ & $\begin{array}{c}\text { S-C } \\
\mathrm{dB} \ddagger\end{array}$ \\
\hline Art. per1. & $0 \pm 0.00$ & $3.38 \pm 0.058$ & $0 \pm 0.00$ & $3.43 \pm 0.060$ & 0 \\
0.15 & $1.2 \pm 1.20$ & $3.36 \pm 0.043$ & $2.4 \pm 1.47$ & $3.37 \pm 0.030$ & 1.2 \\
0.3 & $-2.4 \pm 2.40$ & $3.45 \pm 0.045$ & $6 \pm 1.90$ & $3.41 \pm 0.064$ & 8.4 \\
0.6 & $-1.2 \pm 2.94$ & $3.41 \pm 0.037$ & $12 \pm 1.90 \$$ & $330 \pm 0.042$ & 13.2 \\
125 & $0 \pm 1.90$ & $3.37 \pm 0.058$ & $18 \pm 1.90 \S$ & $3.27 \pm 0.034$ & 18 \\
250 & $0 \pm 4.24$ & $3.34 \pm 0.029$ & $28.8 \pm 2.24 \S$ & $3.21 \pm 0.078$ & 28.8 \\
5 & $-1.2 \pm 3.98$ & $3.40 \pm 0.047$ & $38.4 \pm 2.40 \$$ & $3.00 \pm 0.047 \S$ & 39.6 \\
10 & $3.6 \pm 5.88$ & $3.29 \pm 0.081$ & $43.2 \pm 3.98 \S$ & $2.94 \pm 0.051 \S$ & 39.6 \\
20 & $132 \pm 6.94 \$$ & $3.21 \pm 0.056$ & $54 \pm 4.90 \$$ & $2.86 \pm 0.066 \$$ & 40.8 \\
\hline
\end{tabular}

*Numbers represent the $\mathrm{dB}$ values (mean \pm SE) obtained by subtracting the mean CAP threshold after each treatment from the mean CAP threshold after the predrug artificial perilymph perfusion (art. peri; $n=5$ except for $20 \mathrm{mM}$ control where $n=4$ ).

$+N u m b e r$ represent the $\mathrm{NI}$ latency values (mean $\pm \mathrm{SE}$ ) measured at CAP threshold after each treatment ( $n=5$ except for $20 \mathrm{mM}$ control where $n=4$ ).

†Control $\mathrm{dB}$ values subtracted from salıcylate $\mathrm{dB}$ values to arrive at the effect of salicylate without apparent non-selective effects.

§Indıcate a statıstıcally $(P<0.01)$ signıficant difference from the value obtained for artificial perilymph (art peri.) or $0.15 \mathrm{mM}$ of drug.

same as the concentrations found in the cochlea after systemic administration of aspirin to achieve a blood level necessary to produce a hearing loss (Jastreboff et al., 1986; Thalmann, 1988).

The slight changes in SP and CM were produced by both chemicals only at 10 and $20 \mathrm{mM}$ indicating nonspecific osmotic effects at high concentrations as reported earlier with alpha-ketoglutarate (Jenison et al., 1986). The results on SP and CM are consistent with the lack of effect of salicylate on CM reported by Mitchell et al. (1973), Thalmann et al. (1973) and Thalmann (1975), but are inconsistent with the reduction in CM reported by Silverstein et al. (1967). The SP and CM emanate from hair cells (Dallos, 1985a, b 1986) and reflect the state of these presynaptic elements. The lack of effect of salicylate on SP and CM at low concentrations (less than $10 \mathrm{mM}$ ) indicates a postsynaptic site of action.

The lack of effect on SP and CM is also consistent with salicylate not affecting the endocochlear potential since a change in the endocochlear potential would be expected to decrease CM and SP (Bobbin and Kisiel, 1981). Thalmann et al. (1973) and Thalmann (1975) first showed that salicylate did not affect the endocochlear potential. In addition, they were the first to point out that one of the proposed mechanisms of action of salicylate in other systems-an interference with energy metabolism (Ferreira and Vane, 1974) could not explain the action of salicylate in the cochlea because one of the most sensitive cochlear structures to antimetabolites is the stria vascularis and the endocochlear potential it generates. For example, dinitrophenol (DNP) perfused into the cochlea produces rapid reduction in the endocochlear potential and CM with a concomitant reduction in the CAP (Thalmann et al., 1973; Thalmann, 1975). Therefore we concur with Thalmann and conclude that one can exclude an action on energy metabolism as a mechanism of action for salicylate in the cochlea.

One result obtained in the guinea pig cochlea appears to argue against the hypothesis that salicylate antagonizes the hair cell transmitter in this organ. Our data show that salicylate disrupts the normal two slope pattern of the CAP input-output function: abolishing the segment to low intensity sounds with no effect on the higher intensity segment. The results are consistent with the observations of Thalmann (1975) who reported similar changes in the shape of the C.AP input-output function with intraperitoneal injection of $350 \mathrm{mg} / \mathrm{kg}$ of salicylate. They contrast, however, with those obtained with kynurenic acid, a glutamate antagonist. Kynurenic acid perfused through the guinea pig cochlea reduces CAP amplitude at all sound intensities resulting in a parallel shift in the CAP input-output function (Bobbin and Ceasar, 1987). A parallel shift is consistent with an antagonism of the hair cell transmitter since one would predict that the transmitter would be antagonized at all sound levels. This difference between the affects of salicylate and kynurenic acid on the CAP input-output curve then leads us to question whether salicylate in the cochlea antagonizes the hair cell transmitter, and suggests that we search for an alternative explanation for the mechanism of action for salicylate in the cochlea.

Traditionally the CAP to low-intensity sounds in the cochlea which salicylate abolished has been described as the most sensitive portion of the CAP input-output curve since it is the first part of the curve suppressed by intense sound (Salt et al., 1981) and toxic substances (Aran, 1981; Dallos, 1973). Most evidence indicates that the low intensity CAP reflects the summed activity of single afferent fibers firing at their most sensitive regions to sound stimulation. This region is known as the tip or nonlinear portion of the single afferent fiber tuning curve (Ozdamar and Dallos, 1976). Like the low intensity portion of the CAP curve, the nonlinear portion of the single unit tuning curve is also more sensitive to drugs (Evans and Klinke, 1974), anoxia (Evans, 1974) and intense sound (Cody and Johnstone, 1981). In a study of salicylate on single afferent fiber activity, Evans et al. (1981) and Evans and Borerwe (1982) reported systematic changes in the characteristics of three primary fibers recorded from three cats following intravenous injection of sodium salicylate. They observed about a $25 \mathrm{~dB}$ loss in sensitivity at the characteristic frequencies accompanied by a gradual loss of sharpness in the tip of the tuning curves. Thus the action of salicylate at the level of the CAP and at the level of the single afferent nerve fiber is the same: 
abolishment of the low intensity portion of the CAP input-output function and abolishment of the single nerve tuning at low intensity. Recently it has been hypothesized that the nonlinear portion of the tuning curves and so the low intensity portion of the CAP input-output function reflect an active process (cochlear amplifier) within the cochlea which is required for achieving its sensitivity and frequency selectivity (Davis, 1983; Kim, 1986). Thus it appears to us that in the cochlea the mechanism of action of salicylate involves an action on the active process iteself through an unknown molecular mechanism (e.g. prostaglandin synthesis) or to somehow interfere with its expression at the level of the nerve fibers. Other observations are consistent with this hypothesis. Aspirin consumption in humans and animals reduces delayed evoked otoacoustic emissions (Long et al., 1986; Martin et al., 1988) and reversibly eliminates spontaneous emissions (McFadden and Plattsmeir, 1984; Martin et al., 1988) which appear to depend on an intact active process in the cochlea. Since there is no evidence for an active process in the lateral line it is reasonable that no such action was detected in the lateral line. In addition, it is possible that in the cochlea the active process is more sensitive to salicylate than the hair cell transmitter. Along these lines the active process is thought to be located with the outer hair cells and diffusion of salicylate to this site would seem to be more easily achieved than diffusion to the hair cell transmitter receptor located at the base of the inner hair cells. If this is the case and we could investigate higher concentrations of salicylate, possibly by increasing the perfusion rate, we predict that a kynurenic acid-like action would be observed (i.e. a reduction in both the high and low intensity CAP) which would indicate an action on the hair cell transmitter. Future experiments will explore this possibility.

The increase in N1 latency with salicylate has not been reported previously and was characterized by a shift towards higher intensity at low intensity tone bursts in the latency/intensity function, no change in the N1 latency of CAP evoked by high intensity tone bursts and a shortening of N1 latency at the CAP threshold. We propose that as with our results with the CAP magnitude, all of these changes in N1 latency are consistent with increasing amounts of salicylate decreasing and eventually abolishing the active process or the cochlear amplifier (Davis 1983; Kim, 1986). Davis's model (1983) states that in the normal condition the "... prolongation of latency near threshold beyond what can be explained by the rise time of the stimulus and the traveling wave delay..." is due to the extra time required for the cochlear amplifier resonator ". . . to build up to a full amplitude...". In addition, he implies that as sound intensity increases the latency becomes shorter, in part due to the major site of cochlear partition motion and so nerve fiber activation shifting basalward on the partition from the site of the cochlear amplifier and a dependence on the cochlear amplifier towards a dependence on the passive traveling wave with its shorter latency. Therefore, it appears that the shorter N1 latency at CAP threshold observed after high concentrations of salicylate are consistent with salicylate having abolished the cochlear amplifier of
Davis's model, and so abolishing the prolonged latency occurring at threshold which reflects the latency time required by the resonator of the cochlear amplifier. The fact that N1 latency at CAP threshold changes only slightly or not at all at low concentrations of salicylate can be explained by salicylate only suppressing the cochlear amplifier and so leaving it partially operative. In contrast, the salicylate induced longer N1 latency at a given low intensity or the shift towards higher intensity of the latencyintensity function at low intensity (Fig. 3) is difficult to explain at the present time. When this latency phenomena was observed after intense sound exposure, we hypothesized that the abolishment of the cochlear amplifier slowed the rate of travel of the traveling wave (Puel et al., 1988). We speculate that this also explains the present phenomena observed after salicylate. The lack of effect of high concentrations of salicylate on the N1 latency evoked by high intensity tone bursts is consistent with: (1) the dominance, at high intensity, of the passive traveling wave over the cochlear amplifier which according to the Davis model saturates at about $45 \mathrm{~dB}$ above threshold and, (2) a lack of effect of salicylate on the passive traveling wave and all the cochlear functions associated with it. Thus it appears that in the cochlea all of the actions of salicylate can be explained by an action on the active process or cochlear amplifier of Davis or an action which somehow interferes with its expression at the level of the nerve fibers or the CAP and Ni latency.

In summary, in the lateral line salicylate suppresses spontaneous afferent fiber activity, water motion (natural) evoked activity and the action of L-glutamate and kainate. In the guinea pig, salicylate reversibly suppresses CAP and increases N1 latency at low but not high sound intensities without a detectable affect on CM and SP. We conclude that the mechanism for this action of salicylate may be different in the two animals. In the lateral line the drug may act on the afferent nerve to antagonize the action of the afferent transmitter. In the guinea pig the drug appears to affect the active process and not the afferent transmitter. Whether higher concentrations of salicylate in the guinea pig will produce an effect which resembles that of hair cell transmitter antagonists will be tested in future experiments.

Acknowledgements - Thanks to Cindy Frazier for her aid in the preparation of this manuscript. This work was supported at Kresge New Orleans by NSF research grant BNS-8419241 and the Louisiana Lions Eye Foundation and at Kresge Michigan by Program Project Grant USPHS NS-05785.

\section{REFERENCES}

Aran J.-M. (1981) Electrophysiology of cochlear toxicity. In Aminoglycoside Ototoxicity (Edited by Lerner S. A., Matz G. J. and Hawkins J. E.), pp. 31-47. Little, Brown \& Co., Boston.

Bledsoe S. C., Jr and Bobbin R. P. (1982) Effects of $D-\alpha$-aminoadipate on excitation of afferent fibers in the lateral line of Xenopus laevis. Neurosci. Lett. 32, 315-320.

Bledsoe S. C., Jr, Bobbin R. P. and Puel J.-L. (1988)

Neurotransmission in the inner ear. In Physiology of Hearing (Edited by Jahn A. F. and Santos-Sacchi J. R.), pp. 385-406. Raven Press, New York. 
Bledsoe S. C., Jr, Chihal D. M., Bobbin R. P. and Morgan D. N. (1983) Comparative actions of glutamate and related substances on the lateral line of Xenopus laevis. Comp. Biochem. Physiol. 75C, 119-206.

Bobbin R. P. and Ceasar G. (1987) Kynurenic acid and gamma-D-glutamyl-aminoethylsulfonic acid suppress the compound action potential of the auditory nerve. Hear. Res. 25, 77-81.

Bobbin R. P. and Kisiel D. L. (1981) Physiology of hearing. In Pharmacology of Hearing (Edited by Brown R. D. and Daigneault E. A.), pp. 231-270. John Wiley, New York.

Bobbin R. P. and Thompson M. H. (1978) Effects of putative transmitters on afferent cochlear transmission. Ann. Otol. Rhinol. Laryngol. 87, 185-190.

Bobbin R. P., Bledsoe S. C., Jr and Ceasar G. (1985c) Action of salicylate on the activity of afferent fibers in the Xenopus laevis lateral line. Soc. Neurosci. 11, 244.

Bobbin R. P., Bledsoe S. C., Jr, Chihal D. M. and Morgan D. N. (1981) Comparative actions of glutamate and related substances on the Xenopus laevis lateral line. Comp. Blochem. Physiol. 69C, 145-147.

Bobbin R. P., Bledsoe S.C., Jr, Winbery S. L. and Jenison G. L. (1985a) Actions of putative neurotransmitters and other relevant compounds on Xenopus laevis lateral line. In Auditory Biochemistry (Edited by Dreschen D. G.), pp 102-122. Thomas, Springfield, Illinois.

Bobbin R. P., Bledsoe S. C., Jr, Winbery S., Ceasar G. and Jenison G L. (1985b) Comparative actions of GABA and acetylcholine on the Xenopus laevis lateral line. Comp. Biochem. Physiol. 80C, 313-318.

Cody A. R. and Johnstone B. M. (1981) Acoustic trauma: single neuron basis for the "half-octave shift". J. Acoust. Soc $A m .70,707-719$.

Dallos P (1973) The Auditory Periphery: Biophysics and Physiology, pp. 365-366. Academic Press, New York.

Dallos P. (1985a) Response characteristics of mammalian cochlear hair cells. J. Neuroscl. 5, 1591-1608.

Dallos P. (1985b) The role of outer hair cells in cochlear function. In Contemporary Sensory Neurobiology (Edited by Correia M. J. and Perachio A. A.), pp. 207-230. Liss, New York.

Dallos P. (1986) Neurobiology of cochlear inner and outer hair cells: Intracellular recordings. Hear. Res. 22, 185-198.

Davies J., Jones A. W., Sheardown M. J., Smith D. A. S. and Watkıns J. C. (1984) Phosphono dipeptides and piperazine derivatives as antagonists of amino acidinduced and synaptic excitation in mammalian and amphibian spinal cord. Neurosci. Lett. 52, 79-84.

Davies J., Miller A. J. and Sheardown M. J. (1986) Amino acid receptor mediated excitatory synaptic transmission in the cat red nucleus. J. Physiol. 376, 13-29.

Davis H. (1983) An active process in cochlear mechanics. Hear. Res. 9, 79-90.

Evans E. F. (1974) The effects of hypoxia on the tuning of single cochlear nerve fibers. J. Physiol. 238, 65-67.

Evans E. F. and Borerwe T. A. (1982) Ototoxic effects of salicylates on the responses of single cochlear nerve fibres and on cochlear potentials. Br. J. Audiol. 16, 101-108.

Evans E. F. and Klinke R. (1974) Reversible effects of cyanide and furosemide on the tuning of single cochlear nerve fibers. J. Physiol. 242, 129-131.

Evans E. F., Wilson J. P. and Borerwe T. A. (1981) Animal models of Tinnitus. In CIBA Foundation Symposium 85, Tinnitus, pp. 108-129. Pitman, London.

Ferreira S. H. and Vane J. R. (1974) New aspects of the mode of action of nonsteroid anti-inflammatory drugs. $A$. Ret. Pharmac. 14, 57-73.

Gold A. and Wilpizeski C. R. (1966) Studies in auditory adaptation. II: some effects of sodium salicylate on evoked auditory potentials in cats. Laryngoscope 76, 674-685.

Jastreboff P. J., Hansen R., Sasaki P. G. and Sasaki C. T. (1986) Differential uptake of salicylate in serum, cerebrospinal fluid, and perilymph. Arch. Otolaryngol. Head Neck Surg. 112, 1050-1053.

Jastreboff P. J. and Sasaki C. T. (1986) Salicylate-induced changes in spontaneous activity of single units in the inferior colliculus of the guinea pig. J. Acoust. Soc. Am. 80, 1384-1391.

Jenison G. L., Winbery S, and Bobbin R. P. (1986) Comparative actions of quisqualate and $N$-methyl-D-aspartate, excitatory amino acid agonists, on guinea pig cochlear potentials. Comp. Biochem. Physiol. 84C, 385-389.

Kim D. O. (1986) Active and nonlinear cochlear biomechanics and the role of outer-hair-cell subsystem in the mammalian auditory system. Hear. Res. 22, $105-114$.

Long G. R., Tubis A and Jones K. (1986) Changes in spontaneous and evoked otoacoustic emissions and corresponding psychoacoustic threshold microstructures induced by aspirin consumption. In Peripheral Auditory Mechanisms (Edited by Allen J. G., Hall J. L., Hubbard A., Neely S. T. and Tubis A.), pp. 213-220. SpringerVerlag, New York.

Macht D. I., Greenbery J. and Isaacs S. (1920) The effect of some antipyretics on the acuity of hearing. J. Pharm. exp. Ther. 15, 149-165.

Martin G. K., Lonsbury-Martin B. L., Probst R. and Coats A. C. (1988) Spontaneous otoacoustic emissions in a nonhuman primate. I. Basic features and relations to other emissions. Hear. Res. 33, 49-68.

McCabe P. A. and Dey F. L. (1965) The effect of aspirin upon auditory sensitivity. Ann. Otol. 74, 312-325.

McFadden D. and Plattsmier H. S. (1984) Aspirin abolishes spontaneous oto-acoustic emissions. J. Acoust. Soc. Am. 76, 443-447.

McPherson D. L. and Miller J. M. (1974) Choline salicylate: effects on cochlear function. Arch. Otolaryngol. 99, 305-308.

Mitchell C., Brummett R., Himes D. and Vernon J. (1973) Electro-physiological study of the effect of sodium salicylate upon the cochlea. Arch. Otolaryngol. 98, 297-301.

Mongan E., Kelly P., Nies K., Porter W. W. and Paulus H. E. (1973) Tinnitus as an indicator of therapeutic serum salicylate levels. JAMA 226, 142-145.

Myers E. N. and Bernstein J. M. (1965) Salicylate ototoxicity. Arch. Otolaryngol. 82, 483-493.

Ozdamar O. and Dallos P. (1976) Input-output function of the cochlear whole-nerve action potentials: interpretation in terms of one populate of neurons. J. Acoust. Soc. Am. 59, 143-147.

Puel J. L., Bobbin R. P. and Fallon M. (1988) The active process is affected first by intense sound exposure. Hear. Res. (submitted).

Salt A. N., Konishi T., Cook R. O. and Akay A. (1981) Comparison between the effects of continuous and impact noise on cochlear potentials in guinea pigs. J. Acoust. Soc, Am. 69, 1746-1752.

Silverstein H., Bernstein J. M. and Davies D. G. (1967) Salicylate ototoxicity: a biochemical and electrophysiological study. Ann. Otol. Laryngol. 76, 118-127.

Thalmann R. (1975) Biochemical studies of the auditory system. In The Nervous System. Vol. 3: Human Communication and Its Disorders (Edited by Tower D. B.), pp. 31-44. Raven Press, New York.

Thalmann R. (1988) Personal communication.

Thalmann R., Miyoshi T., Kusakari J. and Thalmann I. (1973) Quantitative approaches to the ototoxicity problem. Audiology 12, 364-382. 